\section{SECOND LAW ANALYSIS OF AUTO CASCADE REFRIGERATION CYCLE USING MIXED HYDROCARBON REFRIGERANT R-600A /R-290/ R170}

Ahmed J. Hamad, Abdul Hadi N. Khalifa*, Hussein Salah

Middle Technical University-Iraq, Engineering Technical CollegeBaghdad
Article history

Received

17 December 2017

Received in revised form

23 May 2018

Accepted

1 August 2018

Published online

5 October 2018

${ }^{*}$ Corresponding author ahaddi58@mtu.edu.iq

\section{Graphical abstract}

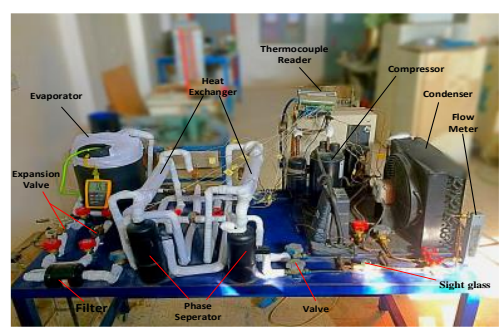

\begin{tabular}{|l|}
\hline \multicolumn{2}{|c|}{ Mixed refrigerant mass fractions } \\
- R-600a/ R-290/ R-170 : $(25.5 / 42.5 / 32) \%$ \\
- R-600a/ R-290/ R-170: $(24.25 / 42.75 / 33) \%$ \\
- R-600a/ R-290/ R170: $\quad(20.5 / 43.5 / 36) \%$ \\
\hline
\end{tabular}

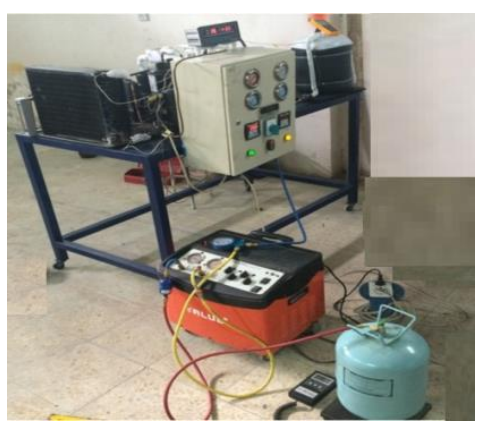

\begin{abstract}
Experimental and theoretical analysis investigations are achieved on the performance of the three-stage auto cascade refrigeration system. Energy and exergy analysis of auto cascade system is considered using zeotropic mixed hydrocarbon refrigerant $\mathrm{R}$ $600 \mathrm{a} / \mathrm{R}-290 / \mathrm{R}-170$ at different mass fractions of (25.5/42.5/32), (24.25/42.75/33), $(23 / 43 / 34)$ and $(20.5 / 43.5 / 36) \%$. The experimental work was performed on test rig for three stages auto cascade refrigeration system of one ton capacity which is designed and constructed for the present study. The theoretical analysis was carried out using a simulation software PROIl based on EES and REFPROP software. The investigated results of the mixed refrigerant R600a/R-290/R 170 have showed an enhancement in COP and cycle capacity by about $12.39 \%$ and $15 \%$ respectively, and the evaporator temperature of the system has approached a relatively lower value of $-60.3^{\circ} \mathrm{Cat}$ mass fraction $(23 / 43 / 34)$ compared to the average value of the other mass ratios. The higher values of the exergy efficiency observed for the condenser, evaporator and compressor were $0.92,0.87$ and 0.7 respectively. Comparison of the auto-cascade performance with $\mathrm{R}$ 600 a/R-290/R-170 at mass fraction (23/43/34) has displayed an enhancement around $45.3 \%$ in the cycle capacity and $39 \%$ reduction in the evaporator temperature compared to the mixed refrigerant R-134a/R-410A at mass fraction (70/30). The theoretical results have displayed a reasonable agreement compared to the experimental results with deviations $33 \%, 22 \%$, and $18 \%$ in COP, cycle capacity and overall exergy efficiency respectively.
\end{abstract}

Keywords: Auto-cascade system, hydrocarbon refrigerant, zeotropic mixture, second law analysis, exergy analysis

2018 Penerbit UTM Press. All rights reserved

\subsection{INTRODUCTION}

The applications of hydrocarbons (HCs) to replace conventional refrigerants in the refrigeration and air conditioning systems have been studied due to their zero ozone depletion potential (ODP) and negligible global warming potential (GWP) [1, 2]. In addition, HCs also have favorable advantages such as availability, non-toxicity, high miscibility with mineral or synthetic oil, etc. [3]. Although the main disadvantage of HCs is their flammability, they may be acceptable by reducing the charge quantity to meet the requirements of safety. Thus, their use as refrigerants in domestic refrigerators is very attractive. In particular, R600a has already been used for domestic refrigerators in Europe and Asia [4]. Also, the applications of R290 in domestic refrigerators are being studied by some companies.

Although there are many studies performed by researchers about pure $\mathrm{HCs}$ as refrigerants in domestic and commercial refrigerators, the use of HCs mixtures of properly chosen components as the refrigerants has also attracted more attention $[5,6]$. Among HCs mixtures, the zeotropic mixtures such as 
$\mathrm{R} 290 / \mathrm{R} 600$ a or $\mathrm{R} 290 / \mathrm{R} 600$ are characterized by a temperature change during phase transitions at constant pressure (typically called temperature glide). The temperature glide exhibited by a zeotropic mixture can be utilized effectively in heat exchangers to reduce irreversibilities, which leads to a better cycle performance [7]. Thus, zeotropic HCs mixtures not only offer the environmentally benign, but also the thermodynamic advantage in improving the energy efficiency of domestic refrigerators. However, previous studies of zeotropic HCs mixtures in domestic refrigerators mainly focused on the applications in a conventional refrigeration cycle (CRC) system. In the CRC, the potential of zeotropic mixtures with the temperature glide feature has been already exploited, where it is the basis of improved cycle performance. In fact, zeotropic mixtures also have the characteristics of composition shift, which can be used to achieve auto refrigerant cascade refrigeration, i.e. the auto cascade refrigeration system uses mixed refrigerants to achieve multilevel cascade through one compressor, which can obtain a low temperature of $-60^{\circ} \mathrm{C}$ and therefore greatly simplify the system [8]. Performance investigation of an auto cascade refrigeration system using zeotropic refrigerant R744/R134a and R744/R290 found that the auto cascade refrigeration cycle has a merit of low operating pressure as low as that in a conventional vapor compression refrigeration cycle. Natural refrigerants with relatively small amount of charge can be used as a refrigerant in the auto cascade refrigeration system [9]. It was concluded that, the natural refrigerants (R290, R1270 and R744) and hydrocarbon/ hydrofluorocarbon refrigerants and their mixtures, would play an important role in air conditioning and heat pump applications [10]. The performance of an ARC refrigerator operating in the liquid refrigerant supply mode with optimized hydrocarbon mixtures and different cascade heat exchangers has been studied. The optimum number of cascade heat exchangers (stages) to be used for different operating temperatures was suggested [11]. The authors of [12] proposed an internal autocascade refrigeration cycle (IARC) operating with the zeotropic mixture of R-290/R-600a or R-290/R-600 for domestic refrigerator freezers. Performances of the auto-cascade refrigeration were evaluated using a developed mathematical model, and then compared with the conventional refrigeration cycle (CRC). According to the simulation results, the IARC with R-290/R-600a has 7.8-13.3\% improvement in coefficient of performance, $10.2-17.1 \%$ improvement in volumetric refrigeration capacity and $7.4-12.3 \%$ reduction in pressure ratio of compressor compared with those of the CRC under the same given operating conditions. The effect of transient heat transfer of a condenser and its effect on a cascade heat pump performance are investigated by the author of [13]. The cascade heat pump consists of the low-temperature refrigeration cycle using R-22 and the high-temperature heat pump cycle using R-134a. The results from the model prediction and experimental investigation have showed that, the heat transfer on the R134a side dominates the total heat transfer mechanism and COP of the heat pump increases with increasing hot water flow rate, leading to the higher efficiency of the heat pump. Exergy analysis being a source to identify the location of major loss and to start improving the performance of any refrigeration system, was used to achieve the exergy analysis of the whole auto-cascade system components [14]. The study was extended to include an extensive comparison between the single stage Joule-Thomson cycle and typical auto-cascade cycle under the same condition. It was found that the total exergy gained during the mixed refrigerant refrigeration cycle was $6.6 \%$ better than the single stage cycle, and $9.5 \%$ better in the situation with distributing heat. The author of [15] have suggested the procedure for exergic analysis and revealed that, R152a performed better in terms of COP, exergetic efficiency, efficiency defect and it substituted the domestic refrigeration system when compared to Ozone Depleting Refrigerants. Since exergic efficiency is higher in the case of system being charged $100 \%, \mathrm{COP}$ is the highest at $50 \%$ charging and refrigerating effect is the highest at $25 \%$ charging. The present study evaluates the theoretical and experimental performance of three stage of autocascade refrigeration cycle (ARC) operating with hydrocarbon zeotropic mixture of R600a/R290/R170 for different mixing mass ratios.

\subsection{METHODOLOGY}

The performance of the auto-cascade refrigeration system depends on various factors, such as the effect of gas-liquid separation, heat transfer of the heat exchanger and mixed working fluids. Performance parameters of the auto-cascade refrigeration system are evaluated in terms of energy

\subsection{Energy Analysis}

The performance of the auto-cascade refrigeration system depends on various factors, such as the effect of gas-liquid separation, heat transfer of the heat exchanger and mixed working fluids. Performance parameters of the auto-cascade refrigeration system are evaluated in terms of energy aspects based on the first law of thermodynamics. The following assumptions are made for the analysis of the autocascade refrigeration system: all components are assumed to be in a steady-state and steady flow process, the compression process in the compressor is irreversible, the evaporator exit vapor and condenser exit liquid are both saturated and refrigerant pressure drop and heat losses in the cycle are neglected. Referring to Figure 1, the work of compressor can be determined by $[16,17]$ :

$$
\begin{aligned}
& \dot{\mathrm{W}}_{\text {comp. }}=\dot{\mathrm{m}}_{\text {comp. }}\left(\mathrm{h}_{2}-\mathrm{h} 1\right) \\
& \dot{\mathrm{m}}_{\text {comp. }}=\dot{\mathrm{m}}_{\mathrm{RI}}+\dot{\mathrm{m}}_{\mathrm{RII}}+\dot{\mathrm{m}}_{\mathrm{RIII}}
\end{aligned}
$$


The heat rejected from the air cooled condenser is calculated as follows:

$\dot{\mathrm{Q}}_{\text {cond. }}=\dot{\mathrm{m}}_{\text {cond. }}\left(\mathrm{h}_{3}-\mathrm{h}_{4}\right)$

Heat absorbed by the evaporator (cycle capacity) can be calculated by:

$\dot{\mathrm{Q}}_{\text {evap. }}=\dot{\mathrm{m}}_{\text {evap. }}\left(\mathrm{h}_{16}-\mathrm{h}_{15}\right)$

The overall performance of the three-stage auto cascade refrigeration system is determined by evaluating the coefficient of performance as follows:

$$
\mathrm{COP}=\frac{\dot{\mathrm{Q}}_{\text {evap. }}}{\dot{\mathrm{W}}_{\text {comp. }}}
$$

\subsection{Exergy Analysis}

Exergy is defined as the maximum amount of valuable energy that can be produced from a process when it comes into equilibrium with its surrounding in a reversible process. A system is in thermal equilibrium with environment when its temperature and pressure are the same for environment. When there is chemical potential with the environment, then the system has zero exergy [18]. System irreversibilities are the reason for exergy destruction and it can be said that, the maximum entropy generation means the maximum exergy destruction [19]. The exergy efficiency frequently gives a finer understanding of performance than the energy efficiency. Exergy efficiency can be defined as a ratio of output exergy to input exergy [20]. Depending on how output and input are defined, different definitions may result for different processes.

Exergy analysis can help engineers in designing and selecting technologies most likely to reduce energy resource consumption in buildings, engines and the application of vapor compression refrigeration cycles. So, the objective of exergy analysis of the three-stage auto cascade system in the current study is to decide the most beneficial parts by enhancements. This is done by identifying the locations of greatest exergy destruction and the components with the lowest exergy or second-law efficiency. Under the assumption that the change of kinetic and potential energy is negligible, the ambient temperature is TO, and referring to Figure 1 and Figure 2 , the exergy is given by the equations:

$\psi_{\mathrm{i}}=\left(\mathrm{h}_{\mathrm{i}}-\mathrm{h}_{0}\right)-\mathrm{T}_{0}\left(\mathrm{~s}_{\mathrm{i}}-\mathrm{s}_{0}\right)$

The compression process is subjected to the nonisentropic compression process, steady state and steady flow process. The thermal and exergy analysis of the rotary compressor can be expressed as [21].

$\Psi_{\text {dest.comp. }}=\dot{\mathrm{m}}_{\text {comp. }}\left(\psi_{1}-\Psi_{2}\right)-\dot{\mathrm{W}}_{\text {comp. }}$

The exergy efficiency of the compressor is the ratio of reversible to actual work.

$\eta_{\mathrm{ex}_{\text {comp }}}=\frac{\dot{\mathrm{m}}_{\text {comp. }}\left|\Psi_{1}-\Psi_{2}\right|}{\left|\dot{\mathrm{w}}_{\text {comp. }}\right|}=1-\frac{\Psi_{\text {dest.comp. }} .}{\left|\dot{\mathrm{w}}_{\text {comp. }}\right|}$
The pressure drop through the condenser is neglected in the exergy analysis. The exergy destruction in condenser is obtained from:

$\Psi_{\text {dest.cond. }}=\dot{\mathrm{Q}}_{\text {cond. }}\left(1-\frac{\mathrm{T}_{0}}{\mathrm{~T}_{\text {cond. }}}\right)+\dot{\mathrm{m}}_{\text {cond. }}\left(\Psi_{3}-\Psi_{4}\right)$

The exergy efficiency of the condenser is expressed as the ratio of the exergy transfer due to heat to the exergy destruction in the refrigerant across the condenser [21]:

$\eta_{\operatorname{ex}_{\text {cond. }}}=\frac{\left|\dot{\mathrm{Q}}_{\text {cond. }}\left(1-\frac{\mathrm{T}_{0}}{\mathrm{~T}_{\text {cond. }}}\right)\right|}{\dot{\mathrm{m}}_{\text {cond. }}\left|\Psi_{3}-\Psi_{4}\right|}=1-\frac{\Psi_{\text {dest.cond. }}}{\dot{\mathrm{m}}_{\text {cond. }}\left|\Psi_{3}-\Psi_{4}\right|}$

The phase separator is assumed to be adiabatic steady state and steady flow process. The exergy destruction in phase separator 1 is obtained from [22]:

$\Psi_{\text {dest.PH.SP } 1}=\dot{\mathrm{m}}_{4} \psi_{4}-\dot{\mathrm{m}}_{5} \psi_{5}-\dot{\mathrm{m}}_{6} \psi_{6}$

And the exergy efficiency is given by:

$\eta_{\text {exph.sp } 1}=\frac{\dot{m}_{5}\left(\psi_{5}-\psi_{4}\right)}{\dot{m}_{6}\left(\psi_{4}-\psi_{6}\right)}$

The exergy destruction and exergy efficiency in the capillary tube 1 are obtained from:

$\Psi_{\text {dest.cap.tube } 1}=\mathrm{m}_{6}\left(\Psi_{6}-\Psi_{7}\right)$

And:

$\eta_{\mathrm{ex}_{\text {cap.tube } 1}}=\frac{\psi_{7}}{\psi_{6}}$

The exergy analysis of the heat exchanger is:

$\Psi_{\text {dest.H.Ex } 1}=\dot{\mathrm{m}}_{9}\left(\psi_{5}-\psi_{9}\right)-\dot{\mathrm{m}}_{7}\left(\psi_{8}-\psi_{7}\right)$

The exergy efficiency of a heat exchanger is the ratio of the increase in the exergy of the cold stream to the decrease in the exergy of the hot stream [23].

$\eta_{\operatorname{ex}_{\mathrm{H} . \mathrm{Ex} 1}}=\frac{\dot{\mathrm{m}}_{7}\left(\psi_{8}-\psi_{7}\right)}{\dot{\mathrm{m}}_{9}\left(\psi_{5}-\psi_{9}\right)}$

The exergy destruction and the exergy efficiency in phase separator 2 are obtained by [22]:

$\Psi_{\text {dest.PH.SP } 2}=\dot{\mathrm{m}}_{9} \psi_{9}-\dot{\mathrm{m}}_{10} \psi_{10}-\dot{\mathrm{m}}_{11} \psi_{11}$

And:

$\eta_{\text {ex } x_{\text {ph.sp } 2}}=\frac{\dot{m}_{10}\left(\psi_{10}-\psi_{9}\right)}{\dot{\mathrm{m}}_{11}\left(\psi_{9}-\psi_{11}\right)}$

The exergy destruction and exergy efficiency in the capillary tube 2 are:

$\Psi_{\text {dest.cap.tube2 }}=\dot{\mathrm{m}}_{11}\left(\Psi_{11}-\Psi_{12}\right)$

And:

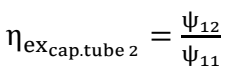


As mentioned in the heat exchangerl, the exergy analysis of the second heat exchanger is:

$\Psi_{\text {dest.H.Ex } 2}=\dot{\mathrm{m}}_{14}\left(\psi_{10}-\psi_{14}\right)-\dot{\mathrm{m}}_{12}\left(\psi_{13}-\psi_{12}\right)$

And the exergy efficiency can be given by:

$$
\eta_{\mathrm{ex}_{\mathrm{H} . \mathrm{Ex} 2}}=\frac{\dot{\mathrm{m}}_{12}\left(\psi_{13}-\psi_{12}\right)}{\dot{\mathrm{m}}_{14}\left(\psi_{10}-\psi_{14}\right)}
$$

The exergy analysis of capillary tube 3 is given by:

$\Psi_{\text {dest.cap.tube } 3}=\dot{\mathrm{m}}_{15}\left(\Psi_{14}-\psi_{15}\right)$

And:

$$
\begin{aligned}
& \eta_{\text {ex }_{\text {cap.tube } 3}}=\frac{m_{15} \psi_{15}}{m_{14} \psi_{14}} \\
&=\frac{\psi_{15}}{\psi_{16}}
\end{aligned}
$$

The exergy destruction in the evaporator is obtained from:

$\Psi_{\text {dest.evap. }}=\dot{Q}_{\text {evap. }}\left(1-\frac{\mathrm{T}_{0}}{\mathrm{~T}_{\text {evap. }}}\right)+\dot{\mathrm{m}}_{\text {evap }}\left(\psi_{15}-\Psi_{16}\right)$

And the exergy efficiency is given by [18]:

$\eta_{\text {ex }_{\text {evap. }}}=\frac{\left|Q_{\text {evap. }}\left(1-\frac{T_{0}}{T_{\text {evap. }}}\right)\right|}{\dot{m}_{\text {evap. }}\left|\Psi_{15}-\psi_{16}\right|}=1-\frac{\Psi_{\text {dest.evap. }}}{\dot{\mathrm{m}}_{\text {evap. } .}\left|\Psi_{15}-\Psi_{16}\right|}$

The total exergy destruction and overall exergy efficiency of the cycle can be determined by considering the auto cascade system as control volume as shown in Figure 2 and given by [24]:

$\Psi_{\text {dest.total. }}=Q_{\text {evap. }}\left(1-\frac{\mathrm{T}_{0}}{\mathrm{~T}_{\text {evap. }}}\right)+Q_{\text {cond. }}\left(1-\frac{\mathrm{T}_{0}}{\mathrm{~T}_{\text {cond. }}}\right)-$

$\dot{\mathrm{W}}_{\text {comp }}$

And:

$$
\eta_{\text {exe-Overall }}=\frac{\left|Q_{\text {evap. }}\left(1-\frac{\mathrm{T}_{0}}{\mathrm{~T}_{\text {evap. }}}\right)\right|}{\left|\dot{\mathrm{W}}_{\text {comp. }}\right|}
$$

The operation of the three-stage auto-cascade refrigeration system with mixed refrigerant R-600a/R$290 / R 170$ considered in the present study is simulated using three software programs, Reference Fluid Properties (REFPROP), Engineering Equation Solver (EES) and Process simulation software (PROII). REFPROP is used to find the thermo- physical properties of the mixed refrigerant, while EES and PROIl are used to build the simulation program.

\subsection{Experimental Work}

A test rig of one-ton capacity auto-cascade refrigeration system is built in the present work to investigate the performance of the system with zeotropic mixed refrigerant. The system setup consists of one rotary compressor, air cooled condenser, shell and coil evaporator, two tube-in-tube heat exchangers, two phase separators, expansion valves, flow meters, pressure gauges, thermocouples with readers and other accessories. The system is at first charged with $2100 \mathrm{~g}$ of $\mathrm{R}-134 \mathrm{a}$ and operated to insure that the system works properly. The system also investigates the performance parameters for comparison purpose with mixed refrigerant. The test rig system is then charged with $870 \mathrm{~g}$ of zeotropic mixed hydrocarbon refrigerant R-600a/R-290/R170 with four mixing mass ratios, namely: $(25.5 / 42.5 / 32)$, $(24.25 / 42.75 / 33),(23 / 43 / 34)$ and $(20.5 / 43.5 / 36) \%$, and the performance of the auto-cascade system is investigated at different operating conditions. The charge of the mixed hydrocarbon refrigerant is determined depending on densities ratio of the hydrocarbon refrigerants compared to R-134a which is based on data of the refrigerant properties and also corresponds to empirical values given by the reference [25]. The accuracy of the measuring devices is shown in Table 1. The schematic diagram of the test rig for auto-cascade refrigeration system is shown in Figure 1.

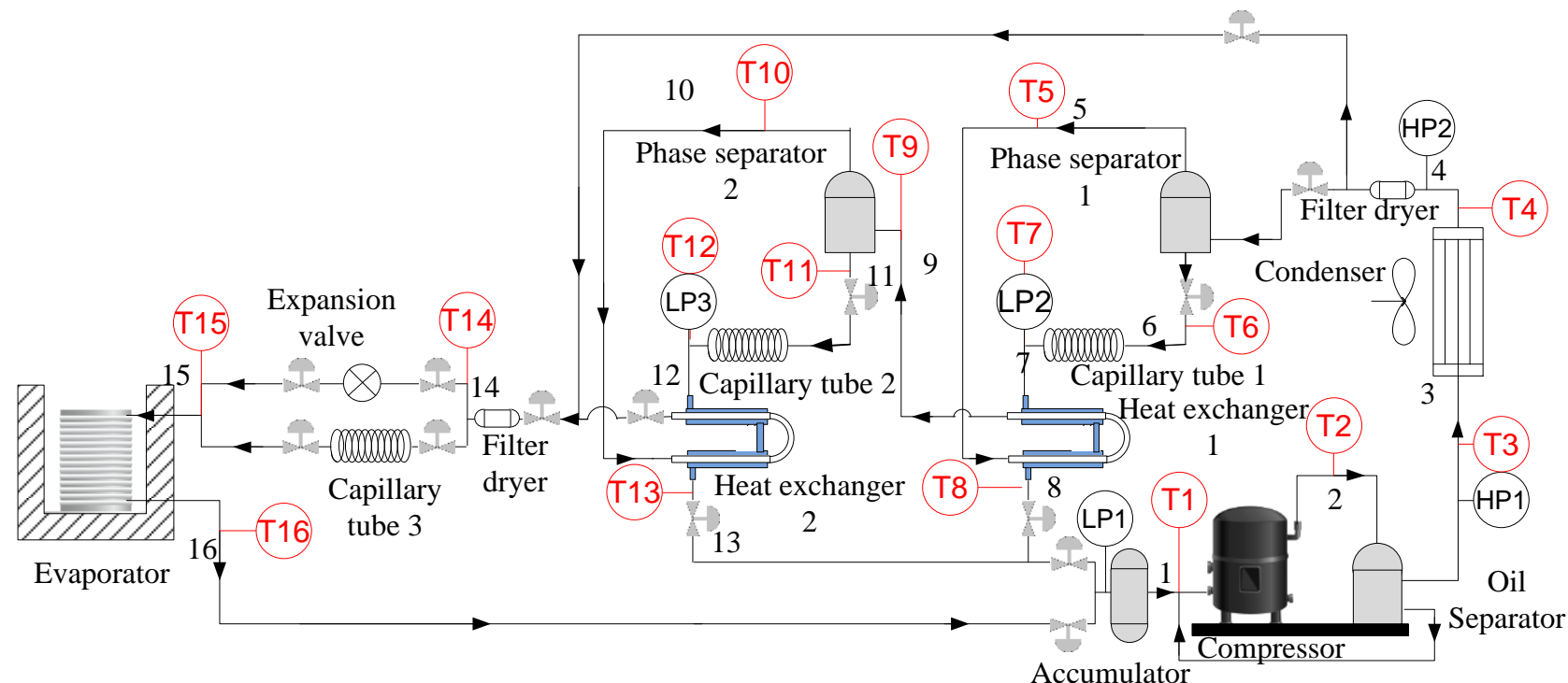

Figure 1 Schematic diagram of the test rig for auto cascade refrigeration system 
Table 1 Accuracy of measuring devices

\begin{tabular}{lc}
\hline \multicolumn{1}{c}{ Instrument } & Uncertainty \\
\hline Pressure gauge & $\pm 0.1 \%$ \\
Temperature (K- type) thermocouple & $\pm 1{ }^{\circ} \mathrm{C}$ \\
Flow meter & $\pm 0.2 \%$ \\
Thermometer & $\pm 1{ }^{\circ} \mathrm{C}$ \\
Current meter & $\pm 1.5 \%$ \\
Digital balance (for refrigerant mass) & $\pm 1 \%$ \\
\hline
\end{tabular}

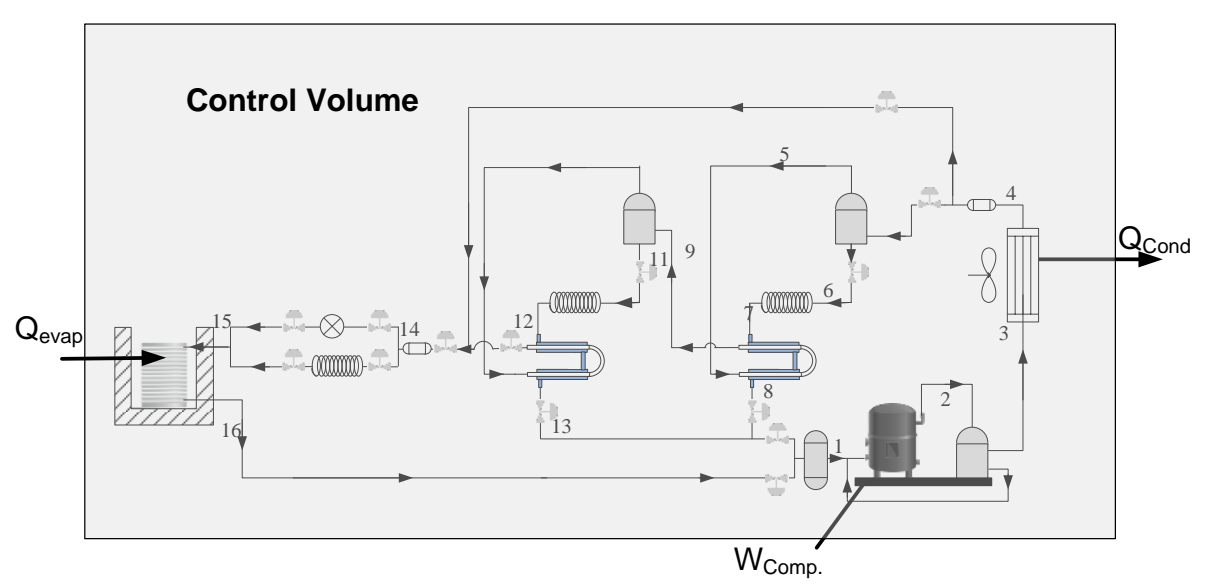

Figure 2 Three-stage auto cascade block system

\subsection{RESULTS AND DISCUSSION}

The theoretical investigation of the auto-cascade cycle performance was achieved by using simulation model based on PROIl software, to determine the optimal mixing ratio for the zeotropic mixed hydrocarbon refrigerant (R600a/R290/ R170) that gives a relatively low evaporation temperature. Figure 3 shows the theoretical results of different mixing ratios for the hydrocarbon mixed refrigerant From this figure it can be conclude that the mass fraction of $(23 / 43 / 34) \%$ approaches a relatively lower evaporation temperature which is about $\left(-63.13^{\circ} \mathrm{C}\right)$ [8]. Figure 4 shows the variation of experimental and theoretical results of COP with mass fractions of mixed refrigerant R-600a/R-290/R-170 for auto cascade refrigeration system. Approximately, similar trend between experimental and theoretical results can be noticed with deviation in range of $33 \%$ due to the assumptions made from the theoretical work.

The COP increases slightly with the increases in the mass fraction of R-170 in the mixture, and the mass fraction $(23 / 43 / 34) \%$ has displayed a higher COP about $12.39 \%$ increase compared to other mass fractions [12]. The reason behind this is due to the fact that, the increase in R-170 leads to enhance the cycle capacity corresponding to compressor power consumption where $\mathrm{R}-170$ represents the most mass fraction in mixture flowing in the evaporator, and as well R-170 gives low boiling temperature at a given pressure. As the mass ratio of $\mathrm{R}-170$ increases more than $34 \%$ in the mixture, the COP decreases significantly because the remaining amount of R-600a is not adequate to condensate all R-290. Since R-290 is used to condensate R-170, the evaporator suffers from refrigerant scarcity. Itis well known that, the refrigerant mass flow rate through evaporator is one of the main parameters that define the cycle capacity [18].

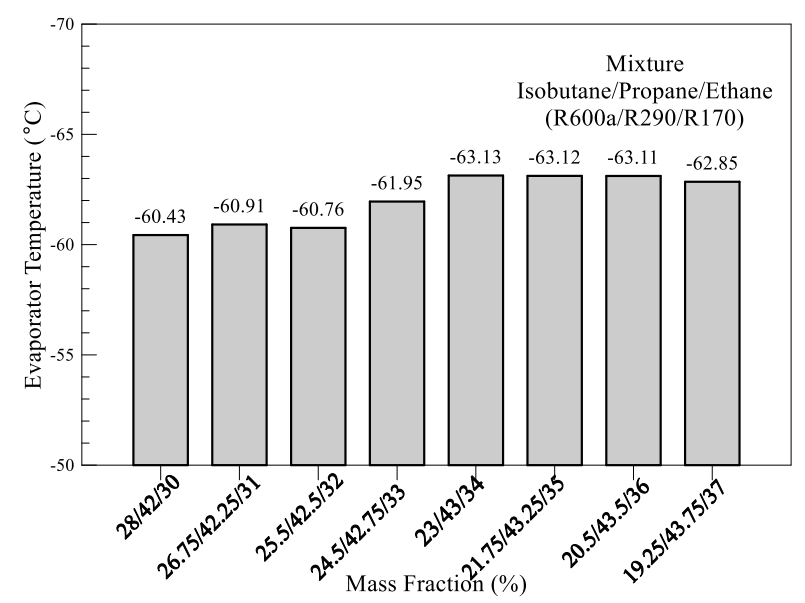

Figure 3 Variation of the evaporator inlet temperature with mass fractions of mixed hydrocarbon refrigerant for the auto-cascade system

The reduction in refrigerant mass flow rate leads to reduce the cycle capacity compared to the compressor power consumption as shown in Figure 5. Since R-170 represents relatively a high pressure refrigerant, then the increase in mass fraction of this refrigerant leads to increase the compressor power consumption compared to other refrigerants in the mixture. The deviation between experimental and theoretical results is about $22 \%$ and $27 \%$ for the compressor power consumption and cycle capacity respectively. 


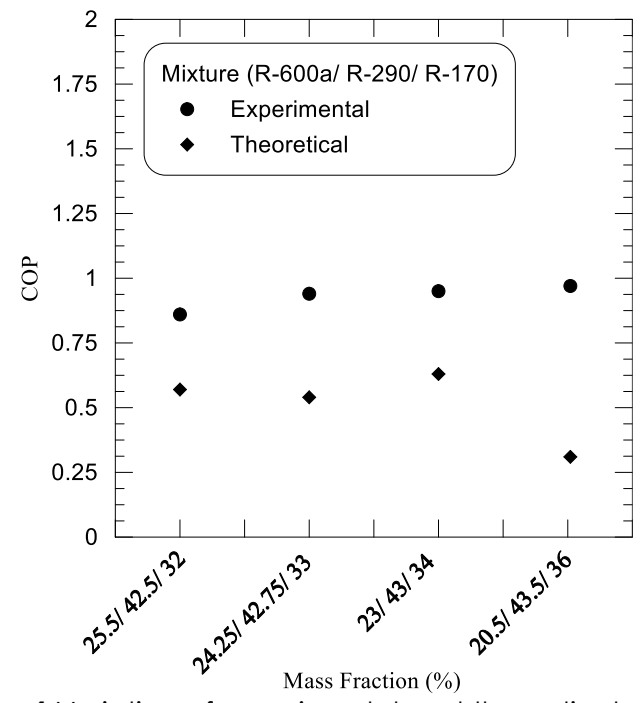

Figure 4 Variation of experimental and theoretical results of COP with mass fractions of mixed hydrocarbon refrigerant

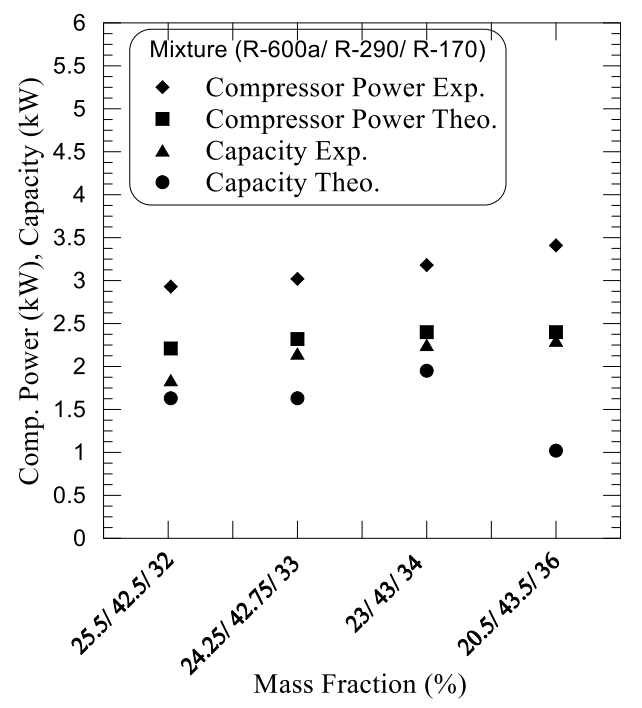

Figure 5 Variations of experimental and theoretical results of compressor power consumption and cycle capacity with mass fractions of mixed hydrocarbon refrigerant

Figure 6 displays the variation of evaporator and discharge temperatures with mass fractions of mixed refrigerant. It can be observed that, the evaporator inlet temperature with mass fraction of $(23 / 43 / 34) \%$ was approached lower value $\left(-60.3{ }^{\circ} \mathrm{C}\right)$ with $7 \%$ reduction in temperature compared to that for other mass fractions [8]. It means that the mass fraction of R-170 is sufficient to extract the heat from evaporator with less degree of superheating, where the mass of R-170 in the evaporator becomes more than the imposed load. Hence, the superheating degree of the vapour leaving the evaporator reduces which reflects positively as a reduction in compressor discharge temperature.

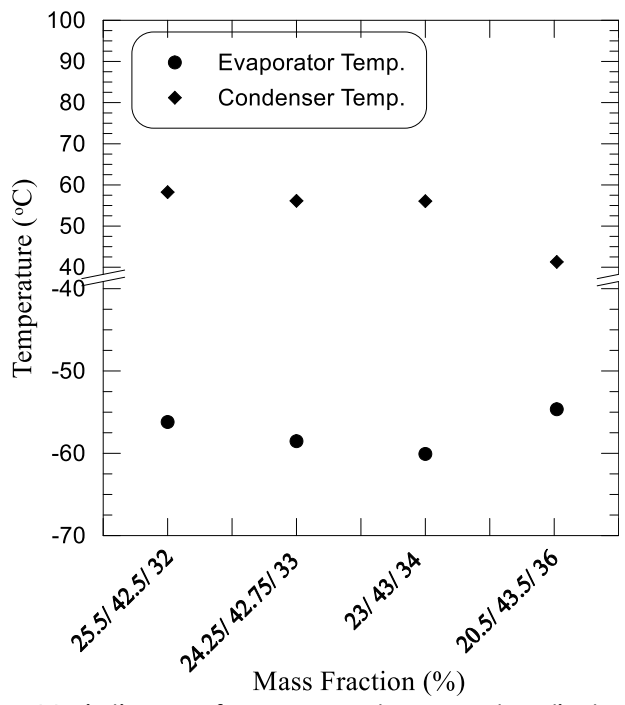

Figure 6 Variation of evaporator and discharge temperatures with mass fractions of mixed hydrocarbon refrigerant

Figure 7 shows the variations of experimental and theoretical results of discharge and suction pressures with mass fractions of mixed refrigerant R-600a/R290/R-170. The deviations between the experimental and theoretical results for suction and discharge pressures are $37 \%$ and $11 \%$ respectively due to neglecting the irreversibility in the compressor and friction loss through pipes and valves for theoretical results. The cycle capacity and evaporator temperature of the auto-cascade system with R$600 a / R-290 / R-170$ at different mass fractions is compared to another mixed refrigerant R-134a/R$410 \mathrm{~A}$ at mass fraction (70/30) \% achieved in the present work to insure the validity of the results as shown in Figure 8. The comparison of R-600a/R-290/R170 at mass fraction $(23 / 43 / 34) \%$ has displayed an enhancement around $45.3 \%$ in the cycle capacity and $39 \%$ reduction in the evaporator temperature compared to that for R-134a/R-410A.

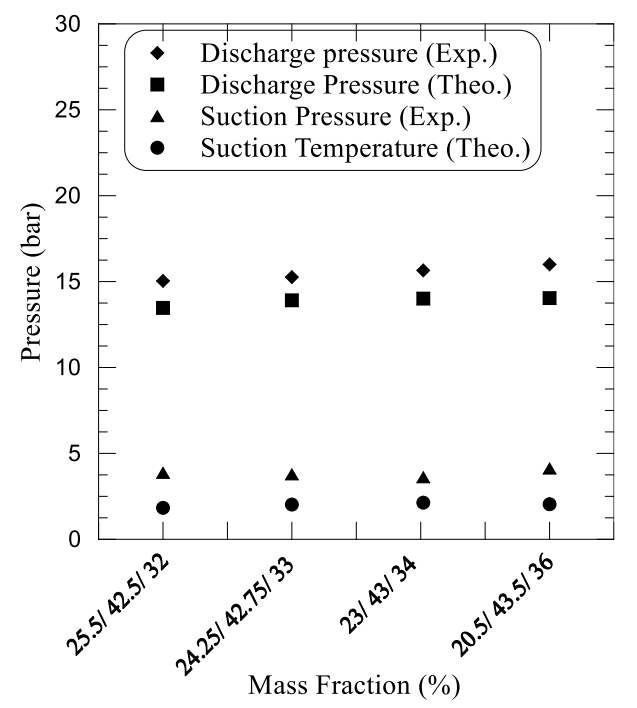

Figure 7 Experimental and theoretical results of the discharge and suction pressures as a function of mass fractions of mixed hydrocarbon refrigerant 


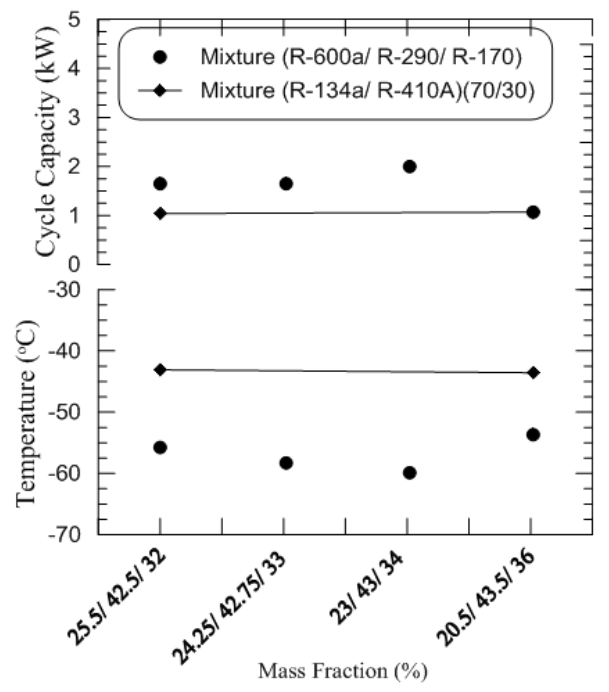

Figure 8 Comparison of cycle capacity and evaporator temperature of the auto-cascade system between mixed refrigerants $R-600 a / R-290 / R-170$ and $R-134 a / R-410 A$ at mass fraction $(70 / 30)$

Figure 9 shows the variation of exergy destruction for auto cascade system main components, compressor, condenser and evaporator with mass fractions of mixed hydrocarbon refrigerant. It is observed that for all mass fractions, the higher value of exergy destruction occurs in the compressor and the lower value is in the condenser. The large exergy destruction in the compressor is due to the entropy generation resulting from high irreversibility caused by friction and heat transfer to environment [14, 15]. The lowest value for the presented results of exergy destruction in the compressor was $0.5029 \mathrm{~kW}$ at mass fraction (23/43/34) \%, which represents $13.29 \%$ lower than other mass ratios. The lower exergy destruction in the condenser occurs when it is operated at high effectiveness, where the condenser temperature is closed to the ambient temperature. The variation of exergy destruction in the evaporator is influenced by two parameters, which are refrigerant mass flow rate and rate of heat transfer. Thus, the low saturation point of R-170 will enhance the heat transfer and increase the exergy destruction in the evaporator.

The variation of exergy efficiency of compressor, condenser and evaporator with mass fractions of the hydrocarbon mixed refrigerant is shown in Figure 10. It can be seen from the figure that the higher exergy efficiency for compressor was 0.7 at mass ratio $(23 / 43 / 34) \%$ with $14.22 \%$ increase compared other investigated mass ratios. The higher exergy efficiency for condenser was 0.92 at mass ratio $(23 / 43 / 34) \%$ with $14.47 \%$ increase compared to other investigated mass ratios, while the relatively higher exergy efficiency for evaporator was 0.87 at mass ratio $(24.25 / 42.75 / 33) \%$. The exergy efficiency of the compressor has displayed a lower value as compared to other components [19], due to the relatively high exergy destruction in the compressor as shown in Figure 9.

Figure 11 shows the comparison between the experimental and theoretical results of the total exergy destruction of the auto cascade system as a function of mass fractions for mixed refrigerant R600a/R290/R170. The total exergy destruction represents a summation of exergy destruction for all components of three stages auto-cascade system. It can be observed that, the exergy destruction increases slightly with the increase in R-170 ratio in the mixed refrigerant and the relatively higher value was $2.25 \mathrm{~kW}$ at $(24.25 / 42.75 / 33) \%$ mass fraction.

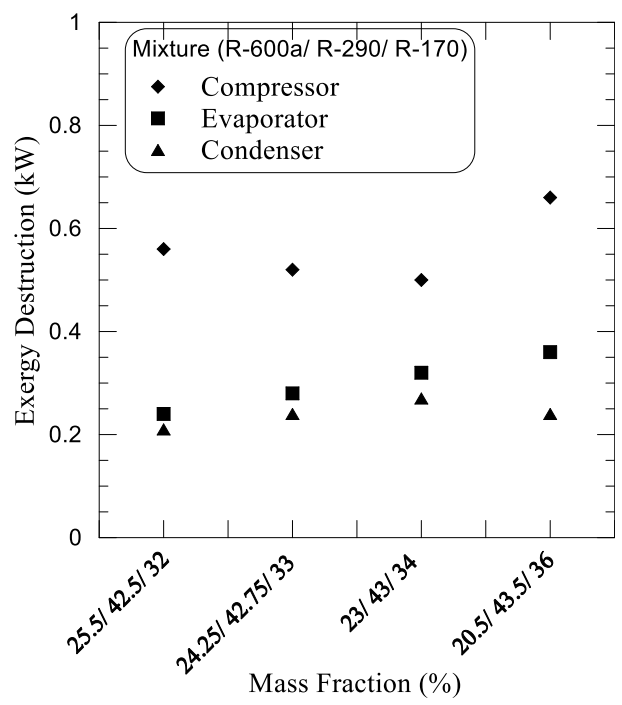

Figure 9 Variation of the exergy destruction for compressor, condenser and evaporator with mass fractions of mixed refrigerant

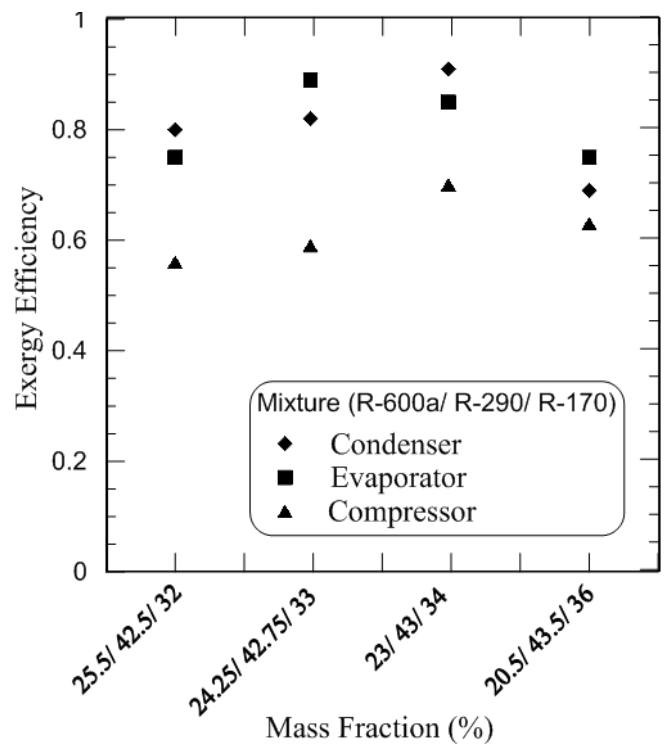

Figure 10 Variation of the exergy efficiency for compressor, condenser and evaporator with mass fractions of mixed refrigerant

It can be observed that the trend of theoretical results is approximately similar to the experimental results with a deviation in range of $32 \%$.

Figure 12 shows the comparison between experimental and theoretical results of the system overall exergy efficiency as a function of mass fractions for mixed refrigerant R600a/R290/R170. It also can be observed that the trend of the system overall exergy efficiency is in contrast to the trend of 
overall exergy destruction of the system that is shown in Figure 11 [23]. At mass fraction of (20.5/43.5/36)\% when the ratio of $\mathrm{R}-170$ in the mixture is equal to $36 \%$, it has displayed the highest overall exergy efficiency for the presented results of the auto cascade system. It can also be seen that the trend of the theoretical results is approximately close to experimental results with a deviation in range of $18 \%$.

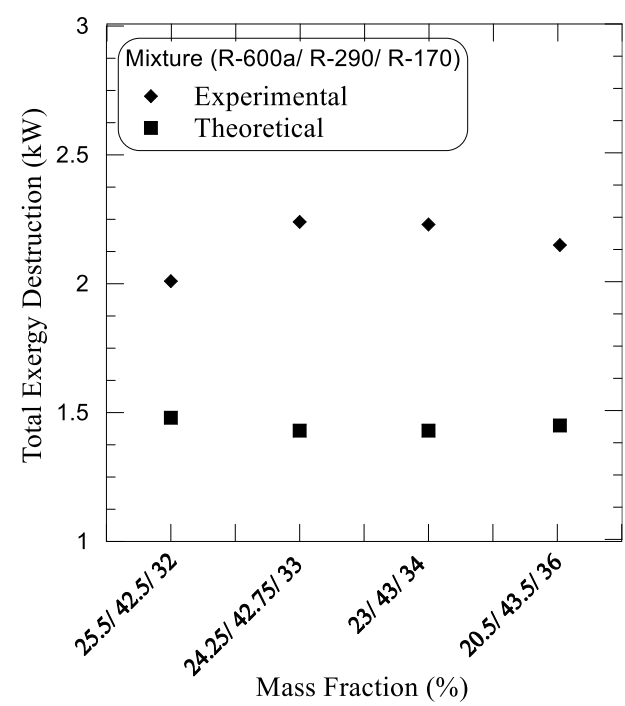

Figure 11 Experimental and theoretical results of the system total exergy destruction as a function of mass fractions of mixed refrigerant R-600a/R-290/R-170

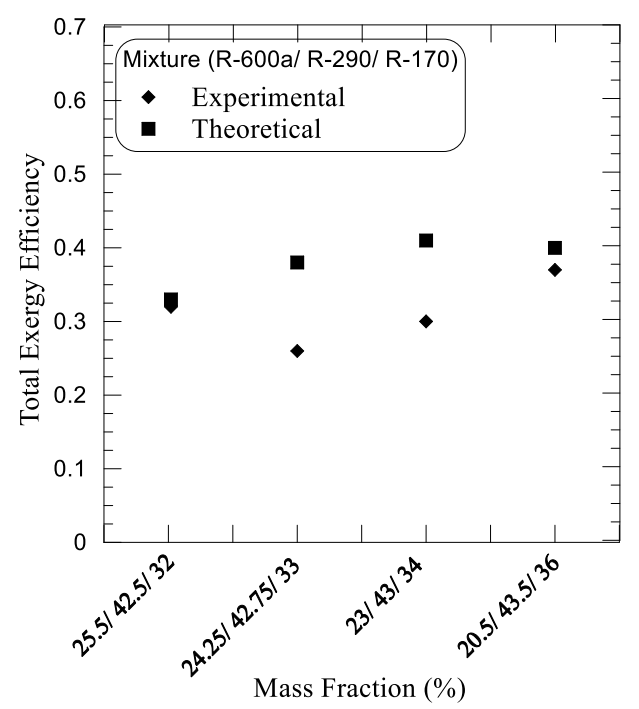

Figure 12 Experimental and theoretical results of the system overall exergy efficiency as a function of mass fractions for mixed refrigerant R-600a/R-290/R-170

\subsection{CONCLUSION}

The used of mixed hydrocarbon refrigerant R-600a/R290/R 170 with different mass fractions has displayed the following conclusions: The enhancement in COP and cycle capacity of the auto-cascade system was $12.39 \%$ and $15 \%$ respectively at mass fraction $(23 / 43 / 34) \%$ compared to other mass ratios. The compressor power consumption and refrigerant discharge temperature increase progressively with increasing of R-170 mass fraction in the mixed refrigerant. The evaporator temperature with mass fraction of $(23 / 43 / 34) \%$ has approached the lowest value $-60.3^{\circ} \mathrm{C}$ with $7 \%$ reduction in the evaporator temperature compared to the average value of the other mass fractions. The higher exergy destruction occurs in the compressor and the lower value is in the condenser. The lowest exergy destruction in the compressor was at mass fraction $(23 / 43 / 34) \%$, on the other hand the higher exergy efficiency observed for the condenser, evaporator and compressor were $0.92,0.87$ and 0.7 respectively. The ratio of $\mathrm{R}-170$ in the mixed refrigerant has a significant influence on performance of the auto cascade system. At mass fraction of $(20.5 / 43.5 / 36) \%$ when the ratio of $\mathrm{R}-170$ in the mixture is equal to $36 \%$, it has displayed the highest overall exergy efficiency. Comparison of the auto-cascade performance with R-600a/R-290/R-170 has displayed an enhancement around $45.3 \%$ in the cycle capacity and $39 \%$ reduction in the evaporator temperature compared to R-134a/R-410A at mass fraction (70/30). The theoretical results have displayed a reasonable agreement compared to the experimental results with deviations 33,22 and $18 \%$ in COP, cycle capacity and overall exergy efficiency respectively.

\section{Nomenclature}

ACC: Air cooled condenser

ACR: Auto cascade refrigeration system

COP: Coefficient of performance

h: $\quad$ Specific enthalpy $(\mathrm{kJ} / \mathrm{kg})$

s: $\quad$ Specific entropy $(\mathrm{kJ} / \mathrm{kg} . \mathrm{K})$

$\dot{\mathrm{m}}$ : $\quad$ Mass flow rate of refrigerant $(\mathrm{kg} / \mathrm{s})$

$\dot{\mathrm{m}}_{\mathrm{RI}}$ : Mass flow rate of refrigerant I $(\mathrm{kg} / \mathrm{s})$

$\dot{\mathrm{m}}_{\mathrm{RII}}$ : Mass flow rate of refrigerant II $(\mathrm{kg} / \mathrm{s})$

$\dot{\mathrm{m}}_{\mathrm{RIII}}$ : Mass flow rate of refrigerant III $(\mathrm{kg} / \mathrm{s})$

Q: $\quad$ Rate of heat transfer $(\mathrm{kW})$

T: $\quad$ Ambient temperature (K)

$\dot{\mathrm{W}}_{\text {comp. }}$ : Compressor Power (kW)

४: $\quad$ Exergy flow $(\mathrm{kJ} / \mathrm{kg})$

$\Psi_{\text {dest. }}$ : Exergy destruction $(\mathrm{kW})$

$\eta_{\mathrm{ex}}: \quad$ Exergy efficiency

Subscripts

comp: compressor

cond: condenser

evap: evaporator

ex: exergy

o: ambient

$1,2,3, \ldots$ locations referring to Figure 1 .

\section{References}

[1] Padalkar, A. S., Kundlik, V. M. and Sukumar, D. 2014. Simulated and Experimental Performance of Split Packaged Air Conditioner Using Refrigerant HC-290 as a Substitute for HCFC-22. Applied Thermal Engineering. 62: 277-284.

DOI: http://10.1016/j.applthermaleng.2013.09.017. 
[2] Rasti, M., Hatamipour, M. S., Aghamiri, S. F. and Tavakoli, M. 2012. Enhancement of Domestic Refrigerator's Energy Efficiency Index using a Hydrocarbon Mixture Refrigerant. Measurement. 45: 1807-1813.

[3] Ahamed, J. U., Saidur, R., Masjuki, H. H. and Sattar, M. A. 2012. An Analysis of Energy, Exergy, and Sustainable Development of a Vapor Compression Refrigeration System Using Hydrocarbon. International Journal of Green Energy. 9(7): 702-717.

DOI: http://dx.doi.org/10.1080/15435075.2011.621491.

[4] Mohanraj, M., Jayaraj, S., Muraleedharan, C., and Chandrasekar, P. 2009. Experimental Investigation of R290/R600a Mixture as an Alternative to R134a in a Domestic Refrigerator. International Journal of Thermal Sciences, 48: 1036-1042.

DOI: http://10.1016/j.ijthermalsci.2008.08.001

[5] Padilla, M., Revellin, R. and Jocelyn B. 2010. Exergy Analysis of R413A as Replacement of R12 in a Domestic Refrigeration System. Energy Conversion and Management. 51 (2): 195-2201.

DOI: http://10.1016/j.enconman.2010.03.013

[6] Yoon, W. J., Kookjeong, S., Chung, H. J., Lee, E. J. and Kim, Y. 2012. Performance Optimization of a Lorenzee Meutzner Cycle Charged with Hydrocarbon Mixtures for a Domestic Refrigerator-Freezer. International Journal of Refrigeration. 35(1): 36-46. DOl: http://10.1016/j.jrefrig.2011.09.014

[7] Xing, J. and Xiaosong, Z. 2011. A New Evaluation Method for Zeotropic Refrigerant Mixtures Based on the Variance of the Temperature Difference Between the Refrigerant and Heat Transfer Fluid. Energy Conversion and Management. 52: 243-249.

DOI: http://10.1016/j.enconman.2010.06.062.

[8] Du, K., Zhang, S., Xu, W. and Niu, X. 2009. A Study on The Cycle Characteristics of an Auto-Cascade Refrigeration System. Experimental Thermal and Fluid Science. 33(2): 240-245.

DOI: http://10.1016/j.expthermflusci.2008.08.006.

[9] Kim, S. G. and Kim, M. S. 2002. Experiment and Simulation on the Performance of an Auto-Cascade Refrigeration System Using Carbon Dioxide as a Refrigerant. International Journal of Refrigeration. 25(8): 1093-110. DOI: http://10.1016/S0140-7007(01)00110-4.

[10] Mohanraj, M., Jayaraj, S., Muraleedharan, C. 2009. Environment Friendly Alternatives to Halogenated Refrigerants-A Review. International Journal of Greenhouse Gas Control. 3: 108-119. DOI: http://10.1016/j.ijggc.2008.07.003

[11] Nayak, H. G. and Venkatarathnam, G. 2010. Performance of an Auto Refrigerant Cascade Refrigerator Operating in Liquid Refrigerant Supply (LRS) Mode with Different Cascade Heat Exchangers. Cryogenics. 50(1 1): 720-727. DOI: http://10.1016/j.cryogenics.2010.07.004.
[12] Yan, G., Hui, H. and Jianlin, Y. 2015. Performance Evaluation on an Internal Auto-Cascade Refrigeration Cycle with Mixture Refrigerant R290/R600a. Applied Thermal Engineering. 75: 994-1000.

DOI: http://10.1016/j.applthermaleng.2014.10.063.

[13] Piman, N. and Chittin, T. 2016. Effect of Transient Heat Transfer of a Condenser on a Cascade Heat Pump Performance. Engineering Journal. (20)3. DOI: https://doi.org/10.4186/ej.2016.20.3.49.

[14] Gong, M. Q., Luo, E. C., Liang, J. T., Zhou, Y. and Wu, J. F. 2002. Thermodynamic Analysis of a Mixed-Refrigerant Auto-Cascade JT Cryocooler with Distributed Heat Loads. Cryocoolers. 11. Springer US: 523-530. DOl: http:// 10.1007/0-306-47112-4_66.

[15] Bolaji, B. 2010. Exergetic Performance of a Domestic Refrigerator. Journal of Engineering Science Technology. 5(4): 435-46.

[16] Wang, H., Peterson, R., Harada, K., Miller, E., Ingram-Goble, R. and Fisher, W. C. 2011. Performance of A Combined Organic Rankine Cycle and Vapor Compression Cycle for Heat Activated Cooling. Energy. 6(1): 447-458. DOl: http://10.1016/j.energy.2010.10.020.

[17] Sivakumar, M., and Somasundaram, P. 2014. Exergy and Energy Analysis of Three Stage Auto Refrigerating Cascade System Using Zeotropic Mixture for Sustainable Development. Energy Conversion and Management. 84: 589-596. DOI: http://10.1016/j.enconman.2014.04.076.

[18] Dincer, I. and Mehmet, K. 2017. Refrigeration Systems and Applications. John Wiley and Sons. DOI: http://10.1002/9781119230793.

[19] Çolpan, C. Ö. 2005. Exergy Analysis of Combined Cycle Cogeneration Systems. Diss. Middle East Technical University.

[20] Boelman, E. C. and Popping, S. 2004. Critical Analysis of Exergy Efficiency Definitions Applicable to Buildings and Building Services. Tc 10:20.

[21] Panahi Zadeh, F. and Navid, B. 2011. The Energy and Exergy Analysis of Single Effect Absorption Chiller. International Journal of Advanced Design and Manufacturing Technology. 4(4): 19-26.

[22] Ghannadzadeh, A. 2013. Exergetic Balances and Analysis in a Process Simulator: A Way to Enhance Process Energy Integration. Doctoral Dissertation, INPT Toulouse.

[23] Dincer, I. and Marc, R. 2007. Exergy, Energy, Environment and Sustainable Development. Applied Energy. 64: 427440. DOI: http:// 10.1016/S0306-2619(99)00111-7.

[24] Claus B. and Sonntag R. E. 2014. Fundamentals of Thermodynamics. 8th Edition. Wiley Global Education. DOI: DOI: http://10.1002/9781118516911.ch5.

[25] Heierli, U. 1997. Refrigeration Appliances Using Hydrocarbon Refrigerants. Manual Prepared by Cool Concerns. ECOFRIG Publication, United Kingdom. 